\title{
Description of cloacoscopy in the loggerhead sea turtle (Caretta caretta)
}

\author{
Filippo Spadola ${ }^{1}$, Manuel Morici $^{1}$, Matteo Oliveri $^{2}$, Zdenek Knotek ${ }^{2}$ \\ ${ }^{1}$ University of Messina, Department of Veterinary Science, Messina, Italy \\ ${ }^{2}$ University of Veterinary and Pharmaceutical Sciences Brno, Faculty of Veterinary Medicine, \\ Avian and Exotic Animal Clinic, Brno, Czech Republic
}

Received September 29, 2015

Accepted December 2, 2016

\begin{abstract}
The aim of the study was to describe cloacoscopy in the loggerhead turtle (Caretta caretta) and to evaluate its efficacy in clinical practice. Cloacoscopy was performed on 31 turtles, 23 females and 8 males. Thirty minutes before anaesthesia, meloxicam $(0.4 \mathrm{mg} / \mathrm{kg})$ was administered intramuscularly. Turtles were anaesthetised with a combination of $0.04 \mathrm{mg} / \mathrm{kg}$ dexmedetomidine and $4 \mathrm{mg} / \mathrm{kg}$ ketamine administered intramuscularly. Cloacoscopy was performed with a diagnostic telescope ( $10 \mathrm{~mm}$ diameter, $30 \mathrm{~cm}$ long, $0^{\circ}$, with an operating sheath) or with a flexible colonoscope (13 $\mathrm{mm}$ diameter, $160 \mathrm{~cm}$ long). Turtles were placed in dorsal recumbence and endoscope was inserted through the vent. In the distal part of the proctodeum, phallus or clitoris were easily visualized. A finger and thumb were placed around the vent to act as a valve in order to control the fluid infusion. Flushing the cloaca with warm saline and $0.6 \%$ lidocaine allowed clear view. The urethral orifice was located centrally within the urogenital sinus. Further proximally, the slit of the urodeum with the distal sphincter of the colon could be visualized. Passing gently through the urethral orifice allowed direct visualization of the urinary bladder. After withdrawing and re-directing the endoscope into the coprodeum, the terminal part of the intestine was reached. From 31 loggerhead turtles examined, fishing lines were found in 23 animals. Cloacoscopy proved to be a feasible diagnostic method and it is suggested as a routine diagnostic tool for clinical assessment of loggerhead turtle patients.
\end{abstract}

Cloaca, chelonians, diagnostic endoscopy

The clinical approach to sea turtles is basically not very different from that of other chelonian groups. However, being wild animals, these patients are easily stressed by invasive techniques (Gregory et al. 1996; Whitaker et al. 1999; Wyneken et al. 2006). It is therefore important to reduce the stress of contact with humans as much as possible. Anaesthesia with extended postoperative recovery periods is also a major challenge. Consequently, all techniques that could reduce the invasiveness of clinical management are of a great value for the veterinary practice involving sea turtles. Endoscopy is a feasible diagnostic technique in clinical practice with reptile patients (Schildger and Wicker 1992; Divers et al. 2010; Hernandez-Divers 2004). Cloacoscopy was described by Coppoolse et al. (1985) and has been rapidly adopted by reptile specialists. The aim of the study was to describe cloacoscopy in the loggerhead turtle (Caretta caretta) and to evaluate its efficacy as a diagnostic tool in clinical practice.

\section{Materials and Methods}

Cloacoscopy was performed in 31 adult loggerhead sea turtles (Caretta caretta), hospitalized for different reasons at the Clinic of Exotic and Wild Animals of the Veterinary Teaching Hospital. All the turtles were found stranded or floating near the island of Sicily. Initial sex determination was based on morphological characteristics (length of the tail, the distance of the cloacal opening to the tip of the tail, presence of the claw on the flipper) and revealed a total of 23 females and 8 males (Table 1). Physical examination with complete neurological examination (Chrisman et al. 1997), evaluation of the blood profile, and radiography were performed (Plate II, Fig. 1) in all turtle patients.

Address for correspondence:

Zdenek Knotek

Avian and Exotic Animal Clinic

Faculty of Veterinary Medicine

University of Veterinary and Pharmaceutical Sciences Brno

Palackeho tr. 1946/1, 61242 Brno, Czech Republic 
Table 1. Basic data on 31 loggerhead sea turtles (Caretta caretta) examined by cloacoscopy.

\begin{tabular}{lccc}
\hline Descriptive statistics & $\begin{array}{c}\text { Curve carapace length } \\
(\mathrm{cm})\end{array}$ & $\begin{array}{c}\text { Curve carapace width } \\
(\mathrm{cm})\end{array}$ & $\begin{array}{c}\text { Body weight } \\
(\mathrm{kg})\end{array}$ \\
\hline Mean & 64.29 & 54.6 & 32.58 \\
Standard deviation & 12.832 & 11.52 & 14.48 \\
Median & 69 & 60 & 34 \\
Minimum & 31 & 26.5 & 9 \\
Maximum & 83 & 67 & 66 \\
\hline
\end{tabular}

Thirty minutes before anaesthesia, meloxicam was administered intramuscularly (IM) at a dose rate of $0.4 \mathrm{mg} / \mathrm{kg}\left(\right.$ Metacam $^{\circledR}$, Boehringer Ingelheim, Germany). Anaesthesia was performed using a combination of $0.04 \mathrm{mg} / \mathrm{kg}$ dexmedetomidine (Dexdomitor ${ }^{\circledR}$, Vetoquinol, Italy) with $4 \mathrm{mg} / \mathrm{kg}$ of ketamine (Ketavet $100^{\circledR}$, Intervet, Italy) administered intramuscularly. Turtles were placed in dorsal recumbence on a heating pad.

Cloacoscopy was performed by using two different scopes: a diagnostic telescope $(10 \mathrm{~mm}$ diameter, $30 \mathrm{~cm}$ long, $0^{\circ}$, Olympus A5254A, Japan) with an operating sheath; and a flexible colonoscope (13 mm diameter, $160 \mathrm{~cm}$ long, Olympus CF-VL, Japan). The scopes were connected to a multi-functional system «TELE PACK $\mathrm{TM}_{\gg}\left(\right.$ Storz ${ }^{\mathbb{B}}$, Tuttlingen, Germany) consisting of a cold light source, a camera, a monitor and a digital picture acquisition system.

After the endoscope was gently introduced into the cloacal opening, sterile saline $\left(30{ }^{\circ} \mathrm{C}, 0.9 \% \mathrm{NaCl}, \mathrm{S} . \mathrm{A} . \mathrm{L} . \mathrm{F}\right.$., Italy) combined with $3 \mathrm{ml} / 1$ lidocaine chlorohydrate ( $2 \%$ Lidocaina, Esteve, Italy), was injected into the cloaca to dilate the cloacal wall to improve visualisation. Subsequently, gentle flushing was performed using a syringe $(60 \mathrm{ml}$, Pic solutions/Artsana, Italy) connected with an intravenous drip line to the operating sheath port of the rigid endoscope or the fibrescope. A finger and thumb were placed around the cloacal opening in order to avoid saline outflow.

\section{Results}

Immediately after the introduction of the tip of the endoscope through the cloacal sphincter, the mucous membrane of the proctodeum and the ventral part of the urodeum with a phallus in the male or a clitoris in the female turtle were easy visualized. Both the phallus and the clitoris consisted of two paired, highly vascular fibrous structures separated by a central trough. Although the clitoris is macroscopically similar in structure to the phallus, the phallus was considerably more developed and bigger in size (Plate II, Fig. 2). No colour differences were observed between the male phallus and the female clitoris. The urethral orifice was located centrally within the urogenital sinus. Further proximally, the slit of the urodeum (Plate III, Fig. 3) with the distal sphincter of the colon could be identified. This slit was formed by two folds covering the urogenital senum. In the dorsal part of the urodeum, a muscular ridge with horizontal fibres was visible (Plate III, Fig. 3). In juvenile turtles, cloacal structures were less developed (Plate III, Fig. 3D).

The endoscope was passed through the urethral orifice to allow direct visual examination of the urinary bladder (Plate III, Fig. 4). The wall of the urinary bladder in the loggerhead sea turtles was so thick it did not allow indirect visual observation of the organs in the coelom, even if a large amount of saline was instilled into the urinary bladder. After withdrawing and re-directing the endoscope into the coprodeum (Plate III, Fig. 5A, B), the terminal part of the intestine was reached (Plate III, Fig. 5D). The intestine was easily identified by the presence of faecal boluses. Before the scope was withdrawn completely from the cloaca, the port of the operating sheath was closed.

Out of the 31 loggerhead sea turtle patients examined, fishing lines (Plate III, Fig. 6) were found in 23 of them (74.19\%). After cloacoscopy was performed, all patients were kept in dry dock tanks for $24 \mathrm{~h}$ for full recovery from anaesthesia. 


\section{Discussion}

Anatomical variations of cloacae among the chelonian species as well as the morphofunctional aspects are poorly documented in literature. Anatomical data regarding the structure of the cloaca, as well as information on developmental changes in gross and ultrastructure properties of the cloaca and annexes, are limited for most sea turtle species (Miller 1985; Limpus 1992; Ceriani and Wyneken 2008). Sea turtle cloacoscopy allows the view of different apparatuses, such the gastrointestinal, reproductive, and urinary, and if an accessible foreign body is present, it allows a minimally invasive removal, similar to esophagoscopy (Pressler et al. 2003). Recently, diagnostic cloacoscopy in sea turtles was performed by Erlacher-Reid et al. (2013) in order to diagnose the intestinal stricture in six green sea turtles (Chelonia mydas). To the authors' knowledge, no cloacoscopy study of loggerhead sea turtles has been found in veterinary literature.

From the medical view, the cloaca is involved in various diseases, such as congenital deformities, microbial and parasitic infections, urolithiasis, neoplasia, foreign bodies, traumas, occlusions, or organ prolapse. As in other chelonians, the sea turtle cloaca is a chamber that receives urine from the kidneys, eggs or sperm from the genital tract, and is connected to the rectum (Fox 1977; Miller 1997). Loggerhead sea turtles have two small accessory bladders connected directly to the urinary bladder; each of these accessory bladders are located lateral to the neck of the urinary bladder (Wyneken 2001). In contrast to the published results of studies dealing with cloacoscopy in terrapins (Emys trinacris and Trachemys scipta elegans) (Jekl et al. 2007; Spadola and Insacco 2009; MartínezSilvestre et al. 2015), it was not possible to reach or observe the accessory bladder in the 31 adult loggerhead sea turtles in our study.

Considering the fragile nature and high susceptibility of this structure to trauma, profound knowledge of cloacal morphology is mandatory in order to perform safe cloacoscopy. A rupture of the urinary bladder or the cloacal wall is a life threatening issue for the patient (Proença and Divers 2015). Several authors (Taylor 2006; Spadola and In sac co 2009) suggested cloacoscopy as a feasible technique for different examinations. The described technique could be an excellent aid for the diagnosis of different cloacal disorders and for the study of the urinary and reproductive tracts (Schildger and Wicker 1989; Jekl et al. 2007). Cloacoscopy could be used for the removal of foreign bodies (calculi or eggs) trapped in the urinary bladder (Knotek et al. 2009; Innis 2010; Mans and Sladky 2012).

Cloacoscopy and cystoscopy have also been proposed as useful methods of sex determination in young chelonians by indirect visualization of gonads through the urinary bladder wall (Selleri et al. 2013). However, it is impossible to observe gonads by cystoscopy in the loggerhead sea turtles because of the thickness of the bladder wall. Sex determination in juvenile sea turtles is a major challenge (Wibbels et al. 1987; Wibbels 2003; Xia et al. 2011). A widely used method of sex determination in chelonians is coelioscopy (Hernandez-Divers et al. 2009; Martínez-Silvestre et al. 2015), which is a mini-invasive method but cloacoscopy could be an even less invasive method for this purpose. Cloacoscopy performed in this study could provide the necessary or additional information to confirm the sex of juvenile sea turtles but it cannot be considered an accurate method such as direct gonads visualization (coelioscopy). Cloacoscopy proved to be a feasible diagnostic method and is suggested as a routine diagnostic tool for clinical assessment of loggerhead turtle patients.

\section{Acknowledgements}

This project received funding from the Faculty of Veterinary Medicine, University of Veterinary and Pharmaceutical Sciences Brno (IGA 1650, 2014). 


\section{References}

Ceriani S, Wyneken J (2008): Comparative morphology and sex identification of the reproductive system in formalin-preserved sea turtle specimens Zoology 111; 179-187

Chrisman CL, Walsh M, Meeks JC, Zurawka H, LaRock R, Herbst L, Schumacher J 1997: Neurologic examination of sea turtles. J Am Vet Med Assoc 211: 1043-1047

Coppoolse KJ, Zwart P 1985: Cloacoscopy in reptiles. Vet Quart 7: 243-245

Erlacher-Reid CD, Norton TM, Harms CA, Thompson R, Reese DJ, Walsh MT, Stamper MA (2013): Intestinal and cloacal strictures in free-ranging and aquarium-maintained green sea turtles (Chelonia mydas). J Zoo Wildl Med 44: 408-429

Fox H 1977: The urogenital system of reptiles. In Gans C and Parsons T (Eds): Biology of the Reptilia. Vol. 6, Morphology E. Academic Press. London, pp. 1-122

Gregory LF, Gross TS, Bolten AB, Bjorndal KA 1996: Plasma corticosterone concentrations associated with acute captivity stress in wild loggerhead sea turtles (Caretta caretta). Gen Comp Endocrinol 104: 312-320

Hernandez-Divers SJ 2004: Endoscopic renal evaluation and biopsy of chelonian. Vet Rec 154: 73-80

Hernandez-Divers SJ, Stahl SJ, Farrell R 2009: An endoscopic method for identifying sex of hatchling Chinese box turtles and comparison of general versus local anaesthesia for coelioscopy. J Am Vet Med Assoc 234: 800-803

Innis CJ 2004: Innovative approaches to chelonian obstetrics. Exotic DVM 6: 8-82

Innis CJ 2010: Endoscopy and endosurgery of the chelonian reproductive tract. Vet Clin N Am Exotic 13: $243-254$

Jekl V, Hauptman K, Knotek Z 2007: Cloacoscopy in chelonians-a valuable diagnostic tool for reproductive tract evaluation. In: Proceedings of the $43^{\text {rd }}$ International Symposium on Diseases of Zoo and Wild Animals. Edinburgh (UK), May 16-20, 2007, pp. 162-163

Knotek Z, Jekl V, Knotkova Z et al. 2009: Eggs in chelonian urinary bladder: is coeliotomy necessary? in Proceedings $16^{\text {th }}$ Annu Conf Assoc Reptilian Amphibian Vet, pp. 118-121

Limpus CJ 1992: The hawksbill turtle, Eretmochelys imbricata, in Queensland: population structure within a southern Great Barrier Reef feeding ground. Wildlife Res 19: 489

Lutcavage ME, Lutz PL 1996: Diving physiology. In: Lutz PL and Musick JA (Eds): Biology of Sea Turtles, CRC Press, Boca Raton. 432 p.

Mans C, Sladky KK 2012: Endoscopically guided removal of cloacal calculi in three African spurred tortoises (Geochelone sulcata). J Am Vet Med Assoc 240: 869-875

Martínez-Silvestre A, Bargalló F, Grífols J 2015: Gender Identification by cloacoscopy and cystoscopy in juvenile chelonians. Vet Clin Exot Anim 18: 527-539

Miller JD 1985: Embryology of marine turtles. In: Gans C, Billett F, Maderson P (Eds): Biology of the Reptilia. Vol. 14 (Development A), Academic Press, New York, pp. 269-328

Miller JD 1997: Reproduction in sea turtles. In: Lutz PL and Musick JA(Eds): Biology of Sea Turtles, CRC Press, Boca Raton, 51 p.

Pressler BM, Goodman RA, Harm CA, Hawkins EC, Lewbart GA(2003): Endoscopic evaluation of the esophagus and stomach in three Loggerhead sea turtles (Caretta caretta) and a Malaysian giant turtle (Orlitia borneensis). J Zoo Wildl Med 34: 88-92

Proença L, Divers S 2015: Comparison between coelioscopy versus cloacoscopy for gender identification in immature turtles (Trachemys scripta). Proceedings of the $2^{\text {nd }}$ International Conference on Avian Herpetological and Exotic Mammal Medicine. April, 18-23, Paris, France, 356 p.

Schildger BJ, Wicker R 1989: Sex determination and clinical examination in reptiles using endoscopy. Herpetological Review 20: 9-10

Schildger BJ, Wicker R 1992: Endoscopy in reptiles and amphibians. Indications, methods, findings.Prakt Tierarzt 73: 516-527

Selleri P, Di Girolamo N, Melidone R 2013: Cystoscopic sex identification of posthatchling chelonians. J Am Vet Med Assoc 242: 1744-1750

Spadola F, Insacco G 2009: Endoscopy of cloaca in 51 Emys trinacris (Fritz et al., 2005): Morphological and diagnostic study. Acta Herp 4: 73-81

Taylor WM 2006: Endoscopy. In: Mader DR (Ed.): Reptile Medicine and Surgery, pp 549-563

Whitaker B, Krum H 1999: Medical management of sea turtle in aquaria. In: Fowler M, Miller RE (Eds): Zoo and Wild Animal Medicine Current Therapy. $4^{\text {th }}$ edn, WB Saunders, New York, pp. 217-231

Wibbels T 2003. Critical approaches to sex determination in sea turtles. In: Lutz PL, Musick JA, Wyneken J (Eds): The Biology of Sea Turtles. Vol. 2, CRC Press, Boca Raton, FL, pp. 103-134

Wibbels T, Owens DW, Morris YA, Amoss MS 1987: Sexing techniques and sex ratios for immature loggerhead sea turtles captured along the Atlantic coast of the United States. In: Witzell WN (Ed.): Ecology of East Florida Sea Turtles. NOAA/National Marine Fisheries Service: NOAA Tech. Rep. NMFS 53, pp. 65-74

Wyneken J 2001: The Anatomy of Sea Turtles. U.S. Department of Commerce NOAA Technical Memorandum NMFS-SEFSC-470, pp. 1-172

Wyneken J, Mader DR, Weber III ES, Merigo C 2006: Medical care of seaturtles. In: Mader DR (Ed.): Reptile Medicine and Surgery. Saunders Elsevier, Philadelphia, pp. 972-1007

Xia ZR, Li PP, Gu HX, Fong JJ, Zhao EM (2011): Evaluating non-invasive methods of sex identification in Green sea turtle (Chelonia mydas) hatchlings. Chelonian Conserv Biol 10: 117-123 
Plate II

Spadola F. et al.: Description of cloacoscopy ... pp. 367-370
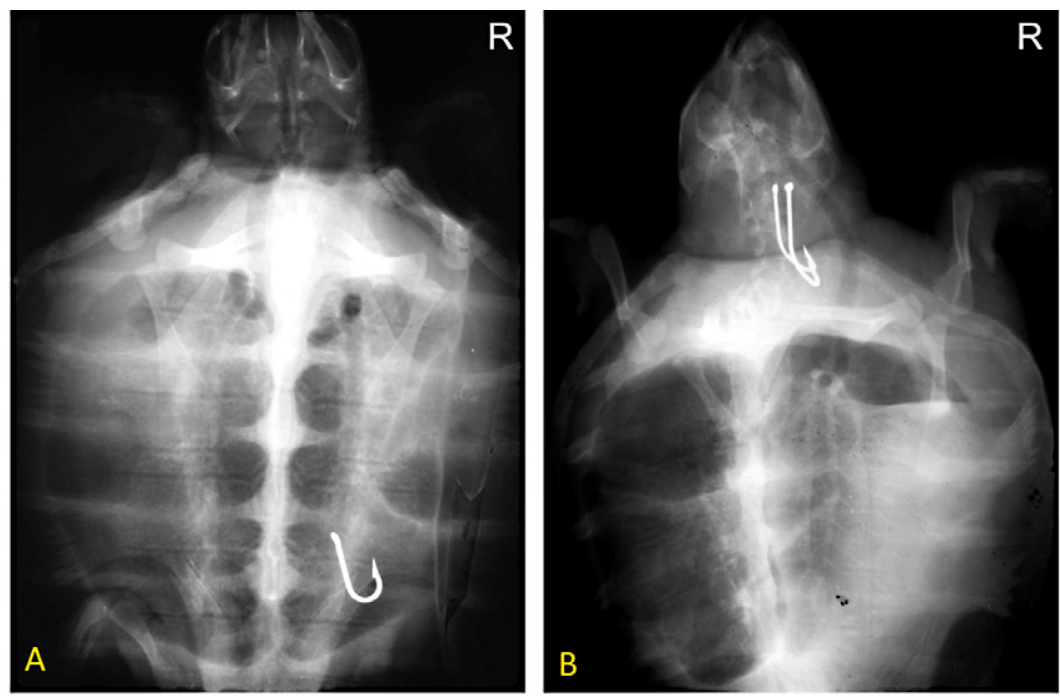

Fig. 1. Whole body radiographies of two female loggerhead sea turtles (Caretta caretta). Note the presence of foreign bodies (fishing hooks) in both radiographs. In the first turtle (A) the hook was trapped in the distal part of the intestine. The second turtle (B) had two hooks trapped in the oesophagus. The presence of hooks was the main cause of stranding.

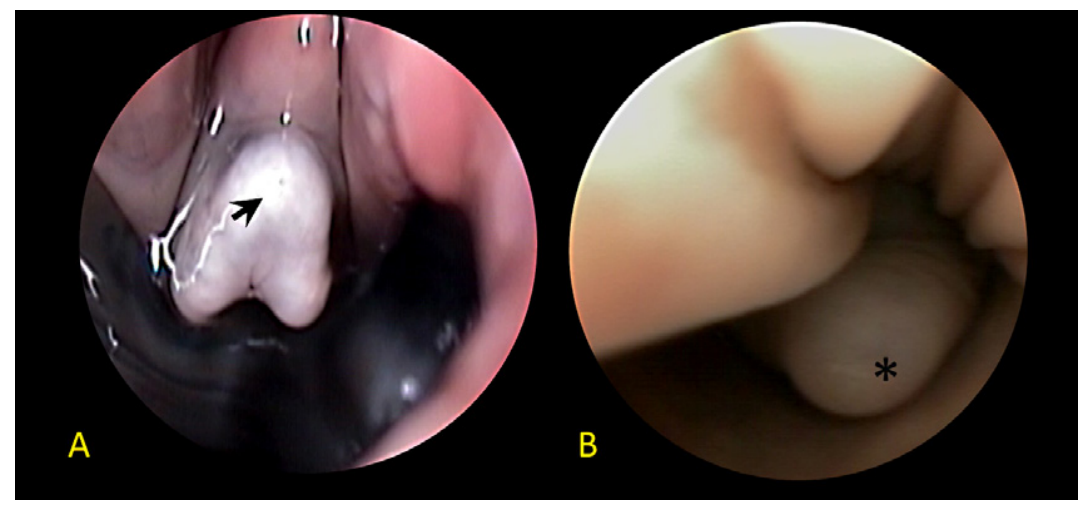

Fig. 2. Cloacoscopic appearance of the genitals in loggerhead sea turtles (Caretta caretta). Note the appearance of the clitoris (arrow) in an adult female loggerhead turtle (A), and of a phallus (asterisk) of an adult male loggerhead turtle (B). Note the different appearance of the phallus, bigger in size and shape. 

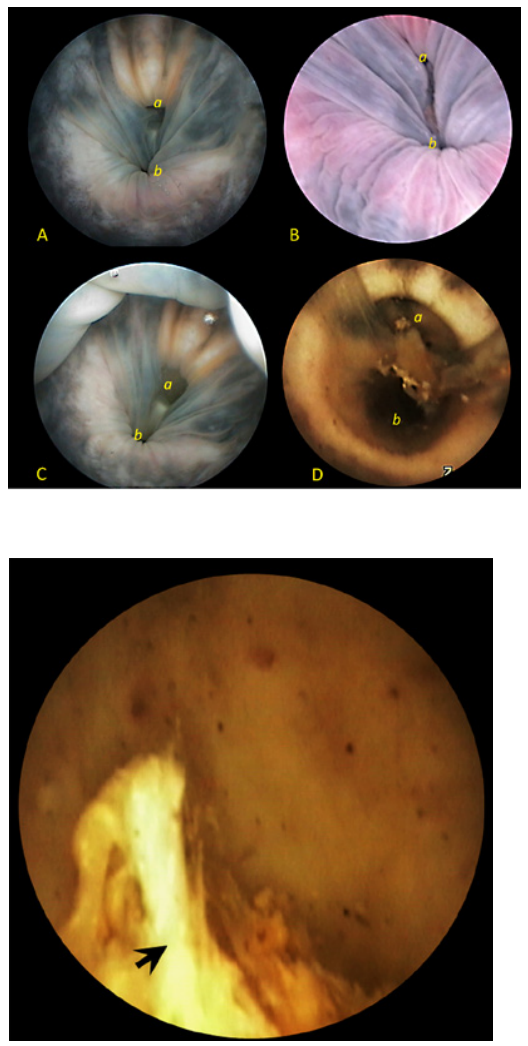

Fig. 4. Cloacoscopic view of the urinary bladder in a loggerhead sea turtle (Caretta caretta), with the presence of precipitation of urine (arrow).

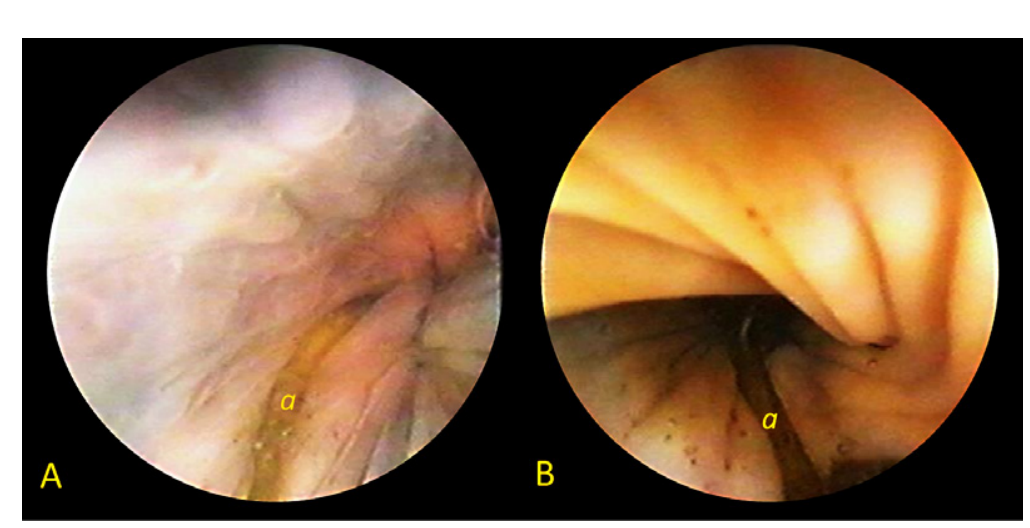

Fig. 6. Cloacoscopic view of fishing lines $(a)$ in the distal colon of the loggerhead sea turtle examined.
Fig. 3. Cloacoscopic view of the coprodeum and urodeum after sterile saline infusion in 4 loggerhead sea turtles (Caretta caretta). The lower part of the picture refers to the dorsal part of the animal. Note the appearance of the urodeum $(a)$ and the distal colon sphincter $(b)$ in adult females (A, B, C). Note the appearance of the urodeum folds covering into the urogenital senum, and the open distal colon sphincter in a young male loggerhead turtle (D).

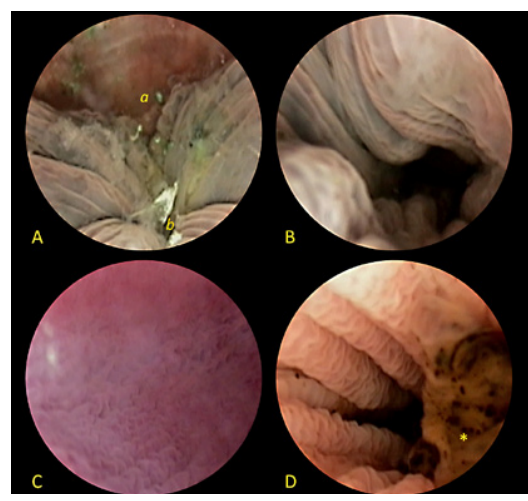

Fig. 5. Cloacoscopic view of coprodeum and the distal colon. Note the close endoscopic view (A) of the distal intestinal sphincter (b). After sterile fluid infusion the intestinal sphincter is dilated (B). The mucosa of the distal colon is full of folds (C). Faecal bolus (asterisk) is present in the intestine lumen (D). 


\section{Erratum to ACTA VETERINARIA BRNO 85, 2016, 4}

Filippo Spadola, Manuel Morici, Matteo Oliveri, Zdeněk Knotek: Description of cloacoscopy in the loggerhead sea turtle (Caretta caretta). Acta Vet Brno 85: 367-370 Incorrect grant agency was mentioned in the Acknowledgement. The correct sentence is:

This project received funding from the Faculty of Veterinary Medicine, University of Veterinary and Pharmaceutical Sciences Brno (Institucionální výzkum 1650, 2014). 